\title{
UHE MACHADINHO E ICTIOFAUNA: IMPACTOS AO LONGO DOS DEZ PRIMEIROS ANOS APÓS A SUA CONSTRUÇÃO
}

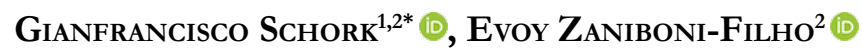

1 Universidade Federal do Sul da Babia (UFSB), Laboratório de Recursos Pesqueiros e Aquicultura (LAPAQ). Rodovia Joel Mares, BR 367, Km 10, s/n, Cx. Postal: 108, CEP: 45.8010-000, Porto Seguro, BA-Brasil.

2 Universidade Federal de Santa Catarina (UFSC), Laboratório de Biologia e Cultivo de Peixes de Agua Doce (LAPAD). Rodovia Francisco Thomaz. dos Santos, $n^{\circ} 3532$ - CEP 88066-260 - Armação do Pântano do Sul - Florianópolis, SC - Brasil.

* Autor para correspondência: gianschork@gmail.com

Recebido em 28 de janeiro de 2020. Aceito em 10 de julho de 2020. Publicado em 31 de julho de 2020.

Resumo - O objetivo deste trabalho foi investigar as alterações ocorridas na assembleia de peixes ao longo dos dez anos subsequentes à formação do reservatório da Usina Hidrelétrica de Machadinho, bacia do Alto Rio Uruguai. Para tal, realizaram-se coletas com periodicidade sazonal entre 2002 e 2011. Ao total, foram capturados 41.168 indivíduos, pertencentes a 7 ordens, 21 famílias, 43 gêneros e 65 espécies. A ictiofauna do reservatório foi dominada por espécies oportunistas, sedentárias e de pequeno porte, sobretudo lambaris e mandis - Astyanax fasciatus e Parapimelodus valenciennis que somaram mais de 48\% dos indivíduos capturados. Quanto à biomassa, o piscívoro Acestrorbynchus pantaneiro foi a espécie mais capturada. A presença de espécies migradoras foi rara, refletindo a ausência de trechos lóticos bem estruturados para garantir os habitats necessários para que estas espécies completem seu ciclo de vida. De uma forma geral, as curvas de k-dominância indicaram uma comunidade de peixes moderadamente perturbada ao longo de todo período de estudo. Quanto às mudanças temporais, a análise de agrupamento indicou alterações graduais da ictiofauna: reflexos dos impactos iniciais causados pelo barramento já no ano de 2002; nova desestabilização da assembleia causada por fatores abióticos em 2006; tendência de estabilização no reservatório nos últimos cinco anos monitorados.

Palavras-chave: Assembleia de Peixes; Alto Rio Uruguai; Conectividade Hidrológica; Impactos Antropogênicos; Usinas Hidrelétricas.

\section{MACHADINHO HPP AND ICTHYOFAUNA: IMPACTS OVER THE FIRST TEN YEARS AFTER ITS CONSTRUCTION}

Aвstract - The aim of this study was to investigate the changes that occurred in the fish assembly over the ten years following the construction of the Hydroelectric Power Plant Machadinho reservoir, in the upper Uruguay River basin. For this purpose, collections were carried out with seasonal periodicity between the years 2002 and 2011. A total of 41,168 individuals were captured, from 7 orders, 21 families, 43 genera and 65 species. The ichthyofauna of the reservoir was dominated by opportunistic, sedentary and small species, mostly "lambari" and "mandi" - Astyanax fasciatus and Parapimelodus valenciennis - which accounted for more than $48 \%$ of the captured individuals. As for biomass, the piscivore Acestrorbynchus pantaneiro was the most captured species. Migratory species was rare, reflecting the absence of well-structured lotic stretches to guarantee habitats necessary for these species to complete their life cycle. In general, the k-dominance curves indicated a moderately disturbed fish community throughout the study period. As for the temporal changes, the cluster analysis indicated gradual changes in the ichthyofauna: reflections of the initial impacts caused by the dam in 2002; new destabilization of the assembly caused by abiotic factors in 2006; trend of stabilization in the reservoir in the last five years monitored.

KEYwORDs: Fish Assemblage; Upper Uruguay River; Hydrological Connectivity; Anthropogenic Impacts; Hydroelectric Plants. 
CH MaChadinho E ICTIOFAUNA: IMPACTOS EN LOS PRIMEROS DIEZ AÑOS DESPUÉS DE SU CONSTRUCCIÓN

Resumen - El objetivo de este estudio fue investigar los cambios que ocurrieron en el ensamblaje de peces durante los diez años posteriores a la formación del embalse de la Central Hidroeléctrica de Machadinho, en la cuenca alta del Río Uruguay. Para ello, se realizaron recolecciones con periodicidad estacional entre 2002 y 2011. En total, se capturaron 41,168 individuos, distribuidos en 7 órdenes, 21 familias, 43 géneros y 65 especies. La ictiofauna en el embalse estaba dominada por especies oportunistas, sedentarias y de talla inferior, especialmente mojarras y porteños (Astyanax fasciatus y Parapimelodus valenciennis respectivamente) que representaban más del $48 \%$ de los individuos capturados. En cuanto a la biomasa, el piscívoro Acestrorbynchus pantaneiro fue la especie más capturada. La presencia de especies migratorias fue rara, lo que refleja la ausencia de tramos lóticos bien estructurados para garantizar los hábitats necesarios para que estas especies completen su ciclo de vida. En general, las curvas de K-dominancia indicaron una comunidad de peces moderadamente perturbada durante todo el período de estudio. En cuanto a los cambios temporales, el análisis de agrupación indicó cambios graduales en la ictiofauna: reflejos de los impactos iniciales causados por la presa en 2002; nueva desestabilización del ensamblaje causado por factores abióticos en 2006; tendencia de estabilización en el embalse en los últimos cinco años monitoreados.

Palabras clave: Ensamblaje de Peces; Río Uruguay Superior; Conectividad Hidrológica; Impactos Antropogénicos; Centrales Hidroeléctricas.

\section{INTRODUÇÃO}

A construção de barragens para geração de energia hidrelétrica é um dos principais impactos antropogênicos causados em bacias hidrográficas, sendo responsável por modificações substanciais na maior parte de seus grandes rios (Zarfl et al. 2014; Winemiller et al. 2016). Problemática evidenciada com especial destaque no Brasil, país que ocupa a segunda posição como maior produtor mundial de energia hidrelétrica (EPE 2017).

Como é de conhecimento, a interrupção do fluxo natural de um rio causa prejuízos para sua conectividade hidrológica e, consequentemente, nas suas transferências de matéria e energia (Vannote et al. 1980; Junk et al. 1989; Ward e Stanford 1995). De forma resumida, como resultado dessas mudanças, entre os efeitos comumente descritos, tem-se: mudanças no aporte de sedimentos e nutrientes, alterações na temperatura e composição química da água, substituição de trechos lóticos por lênticos, além de consequências ecológicas em diferentes níveis (Jorgensen et al. 2013; Santos et al. 2017) que incluem mudanças nos padrões de distribuição da assembleia íctica (Lasne et al. 2007; Miranda e Dembkowski 2015).

Dentro desse cenário, a Bacia do Alto Rio Uruguai tem sido alvo crescente da instalação de usinas que procuram aproveitar sua alta declividade para geração de energia. Localizada no Rio Uruguai, a UHE Machadinho iniciou sua operação em 2002 e possui potência instalada total de 1.140 MW. Parte de um sistema em cascata, o reservatório de Machadinho está sob influência direta de duas usinas situadas a montante, UHE Barra Grande e UHE Campos Novos. Condição que, devido às particularidades dos reservatórios em série sobre as condições limnológicas do rio (Straskraba 1990; Barbosa et al. 1999; Drastik et al. 2008), torna a fragmentação dos seus trechos lóticos já pouco consistentes ainda mais complexa.

Por conseguinte, investigações sobre os impactos da instalação de barragens no Alto Rio Uruguai são realizados desde o início da construção dos empreendimentos na região (Bertoletti e Lucena 1989; ZaniboniFilho e Schulz 2003; Zaniboni-Filho e Nuñer 2008; Nuñer e Zaniboni-Filho 2012; Reynalte-Tataje et al. 2012a; Schork et al. 2013; Schork e Zaniboni-Filho 2017; Schork e Zaniboni-Filho 2018). Entretanto, para avaliar eficientemente os possíveis efeitos irreversíveis e contínuos que ocorrem em longo prazo sobre a assembleia de peixes (e.g. Petesse e Petrere-Junior 2012) é necessário manter um acompanhamento constante do ambiente 
alterado. Assim, o presente trabalho objetivou avaliar a composição e a estrutura da ictiofauna no reservatório de Machadinho ao longo de uma década após a formação do lago.

\section{Material e Métodos}

A Usina Hidrelétrica de Machadinho está localizada no Rio Uruguai, na porção referente ao Alto Rio

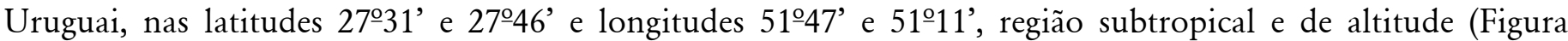
1). O reservatório formado pela usina possui área total de $79 \mathrm{~km}^{2}$, com perímetro aproximado de $509 \mathrm{~km}$ e profundidade média de $30 \mathrm{~m}$, sendo $120 \mathrm{~m}$ a sua profundidade máxima (Néspoli e Pizzato, 2007). Dentro de um sistema cascata de barragens, abaixo da UHE Machadinho encontra-se a UHE Itá e UHE Foz do Chapecó, ambas situadas na calha do Rio Uruguai. À montante, estão localizadas a UHE Barra Grande, no Rio Pelotas, e a UHE Campos Novos, no Rio Canoas.

Figura 1. Localização do reservatório da Usina Hidrelétrica de Machadinho no Rio Uruguai - Bacia do Alto Rio Uruguai, região Sul do Brasil. Os pontos pretos indicam os locais de coleta, denominados MF e MZ no ambiente lêntico e MPB e MC no ambiente de transição.
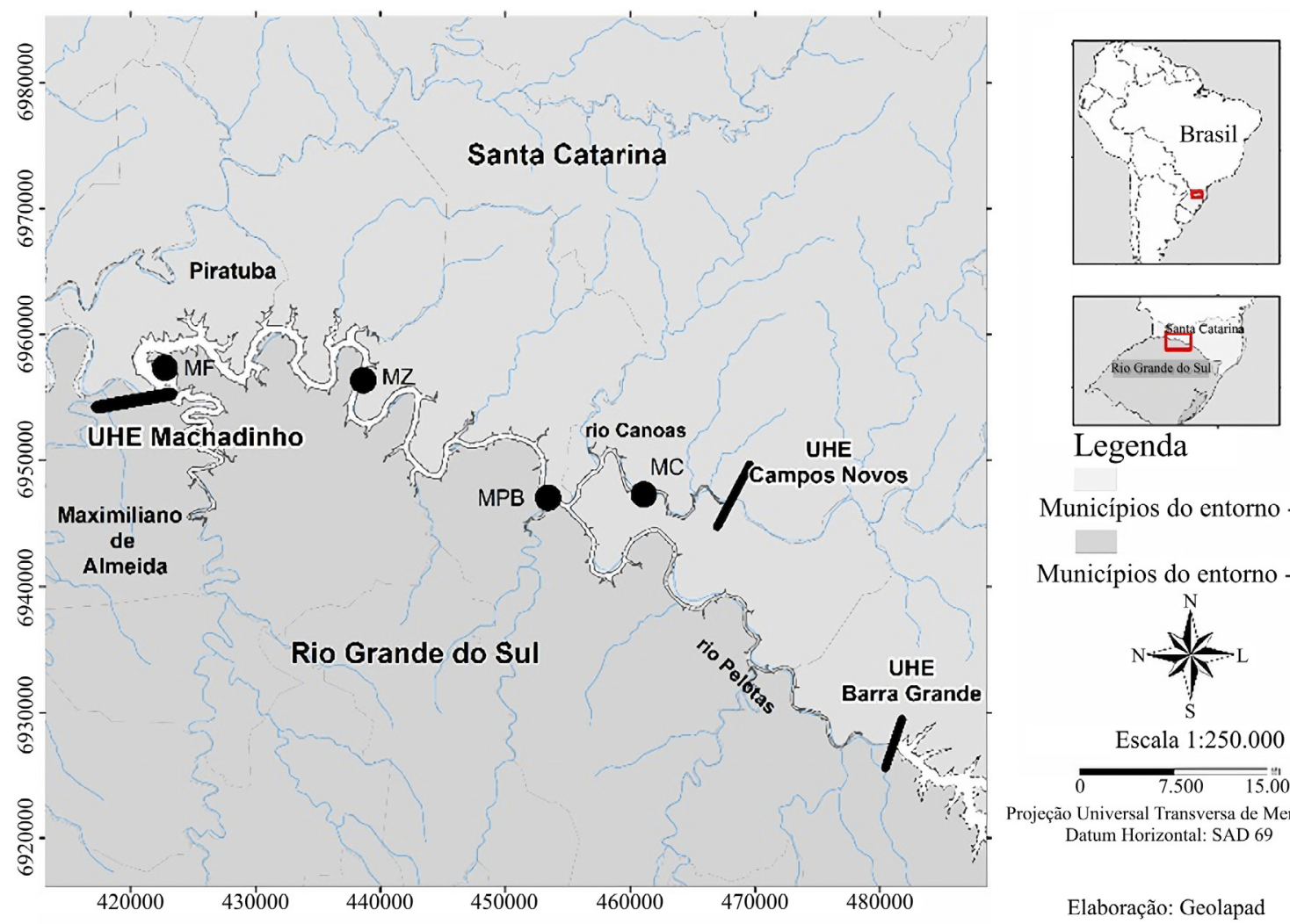

Legenda

Municípios do entorno - SC

Municípios do entorno - RS
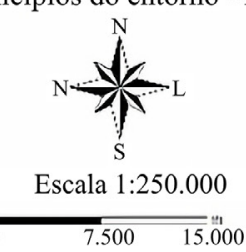

Pjeção Universal Transversa de Mercator Datum Horizontal: SAD 69

Elaboração: Geolapad

As informações foram obtidas no reservatório da UHE de Machadinho através de coletas realizadas com periodicidade sazonal, considerando quatro estações - verão, outono, inverno e primavera -, que iniciaram em janeiro de 2002 e seguiram até dezembro de 2011 (Anexo I). Ao total, ao longo de 10 anos, foram realizadas 40 coletas em quatro pontos amostrais distribuídos entre os diferentes ambientes formados pelo reservatório: lênticos e de transição.

Como petrechos de pesca, foram utilizados nas coletas: redes de espera do tipo malhadeira com malhas de 1,$5 ; 2,0 ; 2,5$ e $3,0 \mathrm{~cm}$ entre nós adjacentes - todas com 1,6 m de altura e comprimento variando de 10 a $30 \mathrm{~m}$ - e redes malhadeiras com malha de $8 \mathrm{~cm}$ entre nós adjacentes, 8 metros de altura e comprimento de 60 e $120 \mathrm{~m}$, denominadas "redes de travessia". Além destas, redes feiticeiras do tipo tresmalho com malhas de 3,0 a 5,0 cm 
entre nós adjacentes, 1,8 m de altura e comprimento de 15 a $40 \mathrm{~m}$. Todas as redes sempre foram colocadas no ambiente ao entardecer e recolhidas ao amanhecer, permanecendo no ambiente por aproximadamente 12 horas. Mesmo procedimento foi utilizado para o espinhel (100 anzóis). Em cada ponto, também foram realizados três lances utilizando redes de arrasto "picaré" (malha de $8 \mathrm{~mm}$ com $7 \mathrm{~m}$ de comprimento) e dez lances de tarrafa (malha $8 \mathrm{~mm}$ e $13.5 \mathrm{~m}$ de diâmetro), sempre durante o dia.

Após a despesca, os exemplares foram identificados até nível de espécie, de acordo com as respectivas chaves taxonômicas, e passaram por biometria - peso total $(\mathrm{g})$ e comprimento total $(\mathrm{cm})$ - ainda em campo. Os exemplares foram então fixados em solução de formalina 10\% e posteriormente conservados em recipientes com etanol 70\%. A coleção contendo os espécimes de peixes da região do Alto Rio Uruguai está depositada junto ao Museu de Zoologia da Universidade Estadual de Londrina (MZUEL).

As amostragens foram licenciadas pelo Ministério do Meio Ambiente e renovadas a cada dois anos (No.52/2007 - CGREP/IBAMA e No.145/2009 - CGFAP/IBAMA).

A estrutura das assembleias foi avaliada através do número (n) de indivíduos, da biomassa (kg), dos índices de riqueza, Shannon-Wiener (H'), equitabilidade (E) e dominância. A constância das espécies foi calculada conforme Dajoz (1973). Complementarmente, determinou-se a curva ABC (Warwick 1986) e a estatística W (Clarke 1990).

Para avaliar as diferenças entre os distintos anos amostrados foram aplicadas análises de variância (ANOVA com medidas repetidas). Anteriormente, os dados foram testados quanto à normalidade (teste de Shapiro-Wilk) e homocedasticidade (teste de Levene). Para atender os pressupostos, os dados de biomassa foram transformados por $\log _{10}(\mathrm{x}+1)$. Na presença de diferenças significativas $(\mathrm{p}<0,01)$, foi aplicado o teste de Tukey para identificar o nível do fator que foi diferente. Quando os pressupostos não foram alcançados, foi aplicado o teste nãoparamétrico correspondente (Friedman ANOVA).

Com o objetivo de verificar variações temporais na composição e na abundância numérica da comunidade, utilizou-se a técnica de ordenação não-métrica - MDS (Clarke e Warwick 2014). Segundo consideração destes mesmos autores, os valores de número de indivíduos foram transformados em $\log _{10}(\mathrm{x}+1)$ preteritamente ao cálculo do índice de similaridade de Bray-Curtis para aproximar a contribuição das espécies raras daquelas muito abundantes nas amostragens.

A análise de similaridade - ANOSIM - foi aplicada para testar a hipótese nula de que não há diferença nas assembleias entre os grupos. Os grupos comparados foram os obtidos pela técnica de ordenação MDS e analisados com níveis de significância de p<0,01 para 9.999 permutações.

Visando determinar a contribuição individual de cada espécie para as dissimilaridades encontradas entre os grupos definidos a priori, procedeu-se a análise de similaridade percentual (SIMPER). De forma a indicar espécies com contribuições consistentes dentro dos anos, a linha de corte foi feita em 50\%.

Para verificar a existência de diferenças na estrutura taxonômica entre os anos, foi calculado o índice de Distinção Taxonômica Média (AvTD $\left.\Delta^{+}\right)$, sendo: AvTD ou $\Delta^{+}=(\Sigma \Sigma i<j \omega i j) /(S(S-1) / 2)$; no qual xi é a quantidade de espécies i; $n=\Sigma i x i$ é o número total de espécies $i$ na área de estudo; $\omega i j$ é o grau de distinção dada pelo comprimento do percurso de ligação das espécies $i$ e $j$ em uma árvore hierárquica; $S$ é o número total de espécies de peixes por amostra (Clarke e Warwick 2001). Para todas as distâncias entre os níveis taxonômicos (espécies, gêneros, famílias, ordens), o peso utilizado para o cálculo de wij foi ponderado e igual a 1 (Clarke e Warwick 2014). Para este índice, considerou-se a presença/ausência das espécies e o intervalo de confiança de 95\% foi obtido de 1000 simulações independentes de subconjuntos randômicos. A lista hierárquica associada com a matriz de dados utilizada para calcular o valor de $\Delta+$ foi elaborada a partir de 105 espécies descritas para a região do Alto Rio Uruguai pelo presente trabalho e outros pretéritos (Zaniboni-Filho et al. 2004; ZaniboniFilho et al. 2008; Reynalte-Tataje et al. 2012b). 


\section{RESUltados}

Ao longo do monitoramento, 41.168 indivíduos foram capturados, com massa total de 2.539,21 kg, pertencentes a 65 espécies, 43 gêneros, 21 famílias e 7 ordens. As ordens Siluriformes ( 25 espécies, 13.953 indivíduos e 767,15 kg), Characiformes (24 espécies, 26.233 indivíduos e 1488,49 kg) e Perciformes (10 espécies, 667 indivíduos e 24,77 kg) foram as mais representativas no reservatório para número de indivíduos, biomassa e espécies capturadas.

Apenas duas espécies foram responsáveis por aproximadamente $48 \%$ da abundância numérica, o lambari Astyanax fasciatus (23,75\%) e o mandi Parapimelodus valenciennis (25\%). Somadas a estas, mais nove espécies ultrapassaram 89\% das capturas. Em ordem crescente: Hypostomus isbrueckeri (2,18\%), Iheringichthys labrosus (2,18\%), Oligosarcus jenynsii (3,34\%), Schizodon nasutus (4,50\%), Bryconamericus iheringii (4,99\%), Astyanax scabripinnis (5,20\%), Astyanax jacubiensis (5,42\%), Steindachnerina brevipinna (5,77\%), Acestrorbynchuspantaneiro (6,76\%). Em relação à biomassa, seis espécies foram responsáveis por mais de 50\% da biomassa das capturas: $A$. pantaneiro $(14,68 \%)$, A. fasciatus (6,65\%), Cyprinus carpio (9,02\%), Hoplias malabaricus (6,54\%), Pimelodus maculatus (7,12\%) e Scbirodon nasutus (10,45\%) (Anexo II).

Quanto à constância nas capturas, apenas quinze espécies foram constantes, sete espécies foram acessórias e o maior número delas (43) foi considerada acidental. Quatro espécies exóticas foram encontradas, a tilápia Oreochromis niloticus, o bagre americano Ictalurus punctatus e as carpas Ctenopharingodon idellus e C. carpio.

Para os peixes considerados grandes migradores, as capturas foram baixas e esporádicas. O dourado Salminus brasiliensis apareceu em capturas nos anos de 2002, 2003, 2004 e 2009. O curimba Procbilodus lineatus foi capturado nos anos de 2005, 2006, 2008 e 2010 enquanto a piracanjuba Brycon orbignyanus foi capturada em 2008, 2009 e 2010. Já a piava Megaleporinus obtusidens teve apenas um indivíduo capturado em 2006.

Comparando os dados anuais de captura ao longo do período de estudo, através da análise ANOVA com medidas repetidas, verificou-se diferença significativa $(\mathrm{p}<0,01)$ entre os valores de número de indivíduos, biomassa $\left(\log _{10}(x+1)\right)$ e riqueza (Figura 2). Houve semelhança $(\mathrm{p}>0,01)$ para os demais índices analisados - dominância, equitabilidade e Shannon H'.

Figura 2. Análise estatística (ANOVA com medidas repetidas), média e erro padrão da riqueza (a), $\mathrm{n}^{\circ}$ de indivíduos (b), biomassa $\left(\log _{10}(\mathrm{x}+1)(\mathrm{kg})\right)(\mathrm{c})$ a partir dos dados de captura de peixes no reservatório de Machadinho no período de 2002 a 2011.
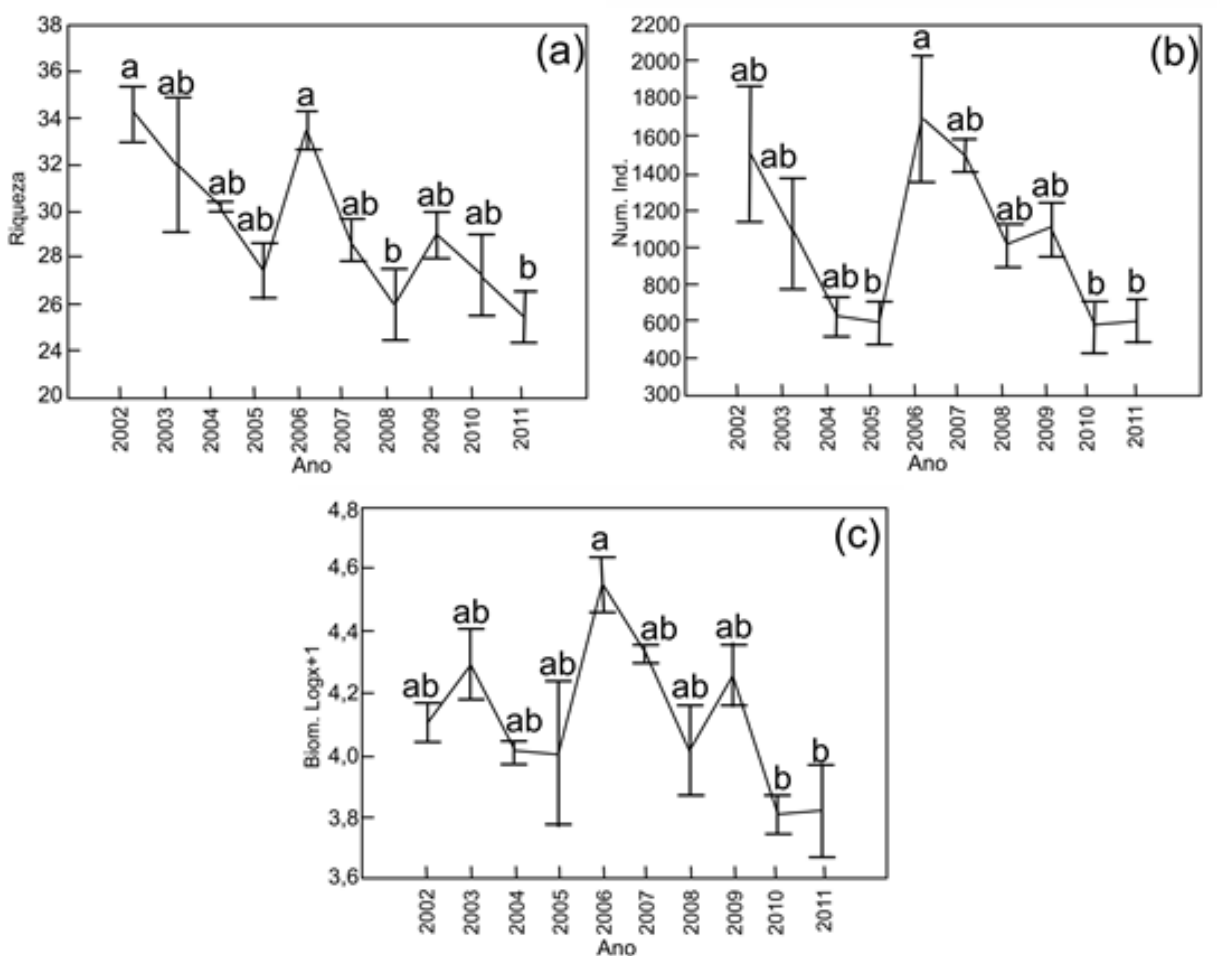

*Letras distintas indicam diferença significativa $(\mathrm{p}<0,01)$. 
A análise de agrupamento com base nos dados de abundância numérica indicou a formação de quatro grupos com uma alta similaridade entre si (+ 80\%). Um grupo formado somente pelo ano de 2002 (G1); outro pelos anos de 2003, 2004 e 2005 (G2); um terceiro por 2006 e 2007 (G3); um quarto pelos anos finais de estudo (2008 a 2011) (G4). Esses mesmos grupos podem ser observados na plotagem bidimensional do MDS, no qual o valor de stress de 0,06 indicou que as distâncias gráficas nas duas dimensões possuem uma excelente representação das similaridades (Figura 3).

Figura 3. Análise de ordenação pelo método MDS baseado nos dados de abundância numérica de todas as espécies capturadas. Grupos delineados no nível de $82 \%$ estão circundados no gráfico de ordenação MDS.

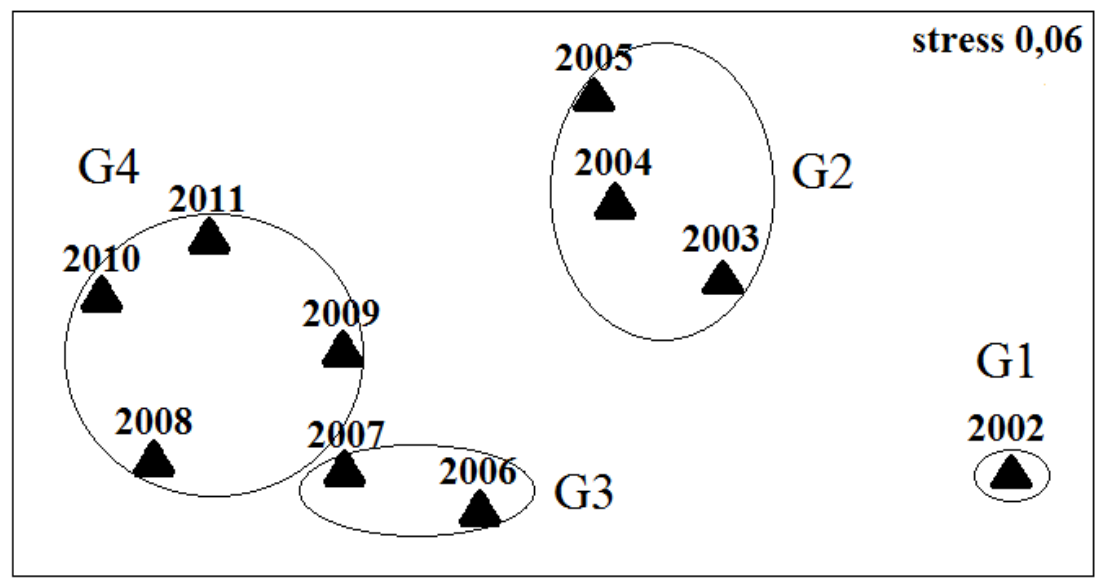

De acordo com a análise de similaridade das percentagens (SIMPER), um total de dez espécies foi responsável por mais de 50\% da dissimilaridade entre os grupos analisados. Dessas, Parapimelodus valenciennis, $A$. pantaneiro, $S$. brevipinna, I. labrosus e $S$. nasutus mostraram aumento das capturas entre os anos iniciais e finais. Diferentemente, A. fasciatus, A. jacubiensis, B. iheringii, A. scabripinnis e $O$. jenynsii apresentaram valores inferiores de captura nos anos finais de estudo.

Todos os valores de AvTD ficaram abaixo da média esperada. Os anos de 2002 e 2006 ficaram fora do intervalo de confiança de 95\% e o ano de 2007 ficou situado exatamente sobre esse limite. Mais próximos da média esperada, assinalam-se os anos de 2008 e 2009 (Figura 4).

Figura 4. Distinção Taxonômica Média calculada para os anos de 2002 a 2011 na UHE Machadinho. A média esperada é indicada pela linha pontilhada central e o limite do intervalo de confiança de $\mathbf{9 5 \%}$ pelas linhas sólidas do entorno.

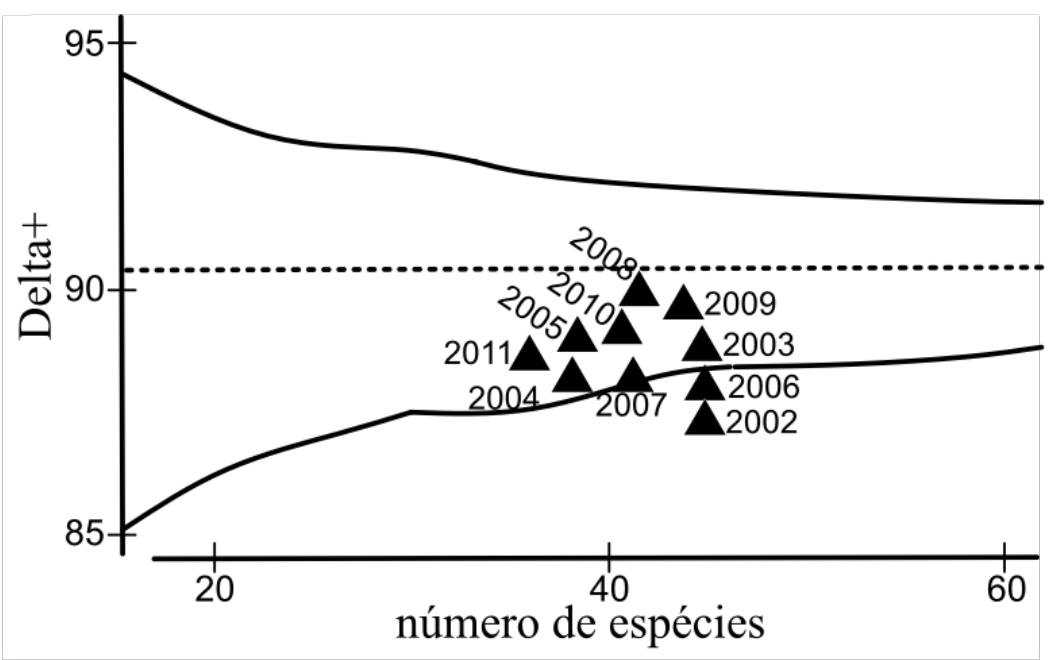


Em todos os anos amostrados após a formação do reservatório de Machadinho, a curva $\mathrm{ABC}$ mostrou a mesma tendência: as duas linhas próximas, porém, a linha da abundância sempre superando a linha da biomassa. Acompanhando este padrão, o cálculo estatístico de W (Clarke 1990) apresentou valores negativos e próximos de zero para todos os anos (Figura 5).

Figura 5. Curva de dominância das espécies "ABC plot” e a estatística W calculadas com base no número de indivíduos e na biomassa total de peixes capturados anualmente no reservatório de Machadinho entre o período de 2002 a 2011.
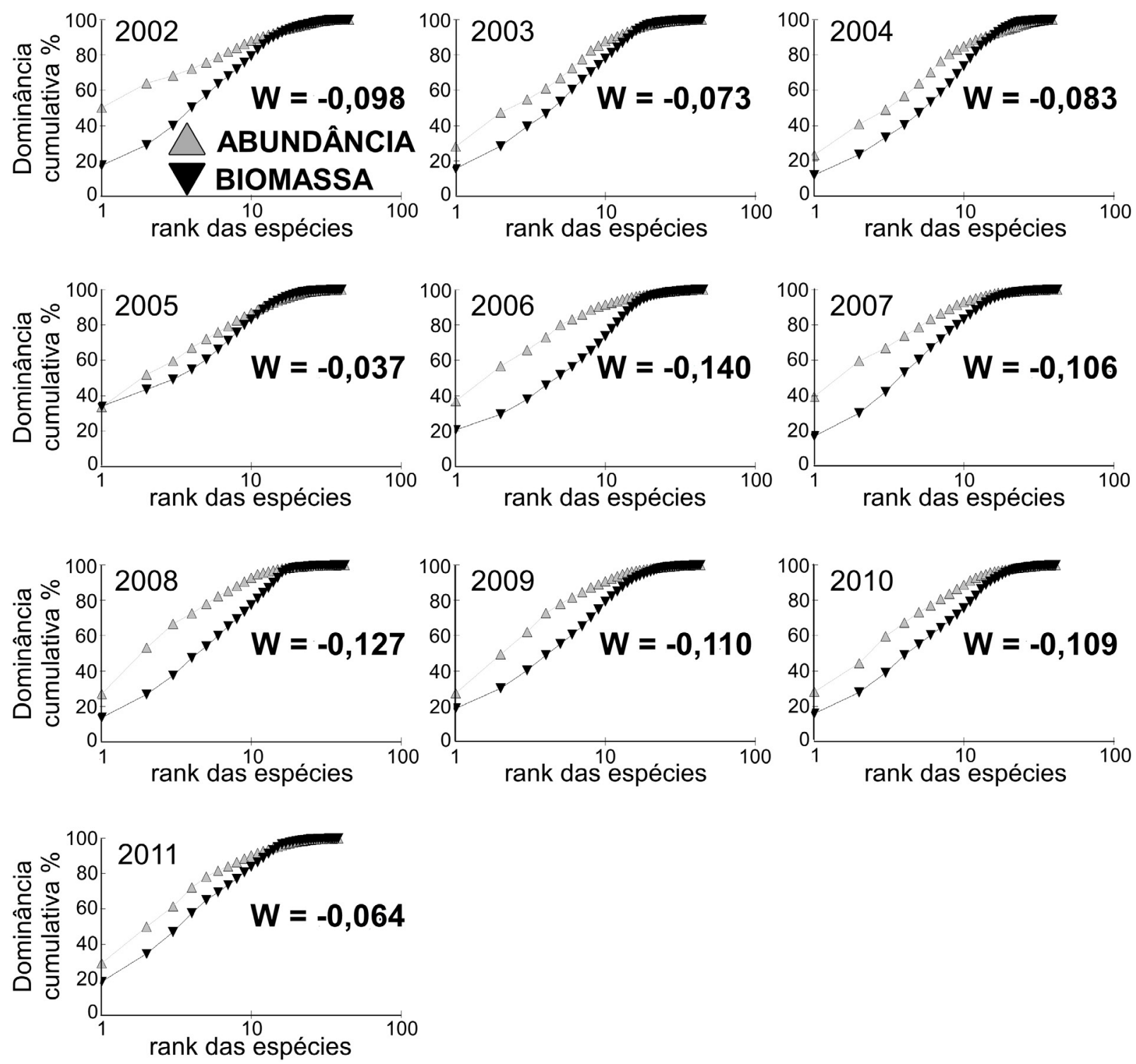

\section{Discussão}

Primeiramente, pôde-se observar os intensos impactos iniciais sofridos pela assembleia íctica no momento seguinte à formação do reservatório, claramente representados por meio dos resultados que afastam o ano de 2002 dos seus subsequentes. Sabe-se que, após o enchimento de um reservatório, ocorre uma grande liberação de nutrientes dissolvidos oriundos da matéria orgânica submersa. Com isso, tem-se uma elevada produção biológica que é sentida em diferentes níveis dentro de um sistema de cascata trófica (Petrere-Junior 1996; Jorgensen et al. 
2013), fato aqui demonstrado pela elevada abundância numérica da ictiofauna em 2002 em relação aos anos posteriores. Observação que corresponde a um mesmo padrão descrito por trabalhos pretéritos no qual ocorre o aumento de algumas espécies com elevada plasticidade comportamental, que se proliferam rapidamente em detrimento de outras com maiores demandas ecológicas (Agostinho et al. 2007; Agostinho et al. 2016).

Da mesma forma, como demonstrado pelos resultados, o ano de 2006 também foi caracterizado por uma nova desestabilização da ictiofauna. Nesse caso, a inferência de maior peso tem relação com o esvaziamento do reservatório da UHE Campos Novos, como resultado de medida técnica empreendida por questões de segurança da construção da barragem. Instalada a montante, a liberação de suas águas represadas pôde ser notadamente observada pela elevação do nível do reservatório de Machadinho a valores próximos da sua cota máxima. Vale ressaltar que, em período anterior ao citado evento, o reservatório de Machadinho operava com capacidade inferior ao normal devido ao período de estiagem que acometia a região. Assim, como discutido acima, neste período também se assinala a proliferação de peixes oportunistas devido ao efeito "bottom-up" que foi impulsionado pelo aporte de água rica em matéria orgânica proveniente do esvaziamento do reservatório à montante.

Apesar dos altos valores de riqueza específica encontrados em 2002 e 2006, baixos valores de distinção taxonômica média foram observados para estes anos, ambos abaixo do limite inferior do intervalo de confiança. Valores de distinção taxonômica média fora do intervalo indicam uma assembleia degradada e com menor biodiversidade, na qual as espécies possuem uma relação taxonômica mais estreita, pertencendo a mesma ordem, família e gênero (Clarke e Warwick 1999). Assim, temos indicação de uma assembleia com uma estrutura mais pobre nestes dois anos, demonstrando impactos mais significantes sofridos pelo ambiente nestes períodos, conforme relação estabelecida pela literatura (Clarke e Warwick 1999; Clarke et al 2014). Cabe notar que os maiores valores de abundância numérica ao longo do tempo foram observados em 2002, 2006 e 2007, resultado que parece não refletir em uma comunidade com maior diversidade de táxons superiores, mas sim, na proliferação de indivíduos de espécies próximas taxonomicamente.

Diferentemente, a partir de 2007, os anos subsequentes ordenam-se mostrando uma mudança gradual da assembleia ao longo do tempo. Com uma estrutura cada vez mais próxima, condição indicativa de que o reservatório aparenta tendência de estabilização.

As curvas de k-dominância da abundância numérica e de biomassa indicaram uma comunidade de peixes moderadamente perturbada ao longo de todo período de estudo. Os valores negativos sempre próximos de zero, indicados pelo cálculo estatístico de $\mathrm{W}$, confirmaram este resultado. A proximidade das curvas de biomassa e de abundância demonstra a representatividade de espécies de pequeno e médio porte não apenas numericamente, como também para a biomassa, e apontam para um discreto desequilíbrio do ambiente. Reflexo de uma ictiofauna dominada por espécies de caráter oportunista, na qual pequenos indivíduos das ordens Characiformes e Siluriformes são os mais representativos. Aqui, mais uma vez, esta característica parece se intensificar no ano de 2006, no qual observamos os menores valores de W.

Nas capturas realizadas na UHE Machadinho, houve dominância de espécies das famílias Characidae Astyanax fasciatus, Astyanax jacubiensis, Astyanax scabripinnis, Bryconamericus iheringii - e Pimelodidae - Iheringichthys labrosus, Parapimelodus valenciennes -, espécies de pequeno porte, classificadas como sedentárias ou migradores de curta distância. Sabe-se que, com a interrupção do curso natural de um rio, espécies menos dependentes de trechos lóticos para completar o seu ciclo de vida conseguem manter mais eficientemente as suas populações ao longo do tempo (Agostinho et al. 2007; Agostinho et al. 2016) e, por isso, tendem a dominar a assembleia de peixes, situação que é aqui reiterada.

A composição da ictiofauna colonizadora de um reservatório é diretamente relacionada à existência de espécies pré-adaptadas ao modo de vida lacustre em seus rios formadores (Fernando e Holcik 1991). Tal padrão é confirmado na formação do reservatório de Machadinho, onde espécies relatadas anteriormente para a região do Alto Rio Uruguai (Godoy 1987; Bertoletti e Lucena 1989; Zaniboni-Filho et al. 2004; Zaniboni-Filho et al. 
2008; Reynalte-Tataje et al. 2012b), com características oportunistas capazes de aproveitar a ampliação da área alagada e a formação de novos habitats, foram as que obtiveram maior sucesso na colonização da área. Dentre estas, destacam-se Astyanax fasciatus e Parapimelodus valenciennis, típicas da região, e que alternaram a dominância da assembleia ao longo dos anos subsequentes à formação do reservatório.

Astyanax fasciatus pode ter seu sucesso relacionado à sua flexibilidade ecológica, que combina amplo espectro alimentar e estratégias reprodutivas que incluem a produção de numerosos ovos adesivos com rápido desenvolvimento e longos períodos de desova (Dias et al. 2005; Hirt et al. 2011). Já o aumento na abundância de Parapimelodus valenciennis pode estar relacionado à maior disponibilidade de alimento para esta espécie, de hábito planctívoro (Almeida et al. 2013), uma vez que a produção de plâncton é favorecida pelas novas condições hidrodinâmicas no ambiente do reservatório.

Quanto aos peixes considerados como migradores de longa distância, apenas quatro espécies foram encontradas, todas com baixas capturas. Como é de conhecimento, peixes migradores, na busca de locais adequados para desova, deslocam-se para montante dos rios. Assim sendo, as barragens aparecem como um obstáculo aos seus trajetos e, por consequência, ao sucesso de seu ciclo de vida, o que logicamente afeta negativamente a abundância de suas populações (Agostinho et al. 2007). No reservatório de Machadinho, a ausência de tributários importantes e a quase inexistência de áreas lóticas na sua porção superior, devido à presença de barramentos em cascata em seus principais rios formadores, certamente tem dificultado ainda mais o ciclo reprodutivo destas espécies. Circunstância que pode ser exemplificada pelo trabalho de Hermes-Silva et al. (2012) que relataram a ausência de larvas de peixes migradores na área deste reservatório.

Quanto às capturas esporádicas de grandes migradores, inclusive em anos muito posteriores ao fechamento do reservatório, discute-se sua relação com eventos de soltura. Em ocasiões distintas, foram realizadas solturas experimentais de juvenis de dourado, curimba e piava, e adultos de dourado - informações registradas nas autorizações expedidas pelos órgãos ambientais (№145/2009 - CGFAP/IBAMA; № 251/2010 - CGFAP/IBAMA; № 016/2011 - DILC/IBAMA/MMA). Além disso, solturas de poucos indivíduos de espécies migradoras, realizadas de forma independente por pescadores artesanais, também já foram relatadas na área de estudo (Schork et al. 2013).

Também merece atenção, as capturas de Brycon orbignyanus, espécie classificada como ameaçada de extinção, de acordo com a Lista da Fauna Brasileira Ameaçada de Extinção (MMA, 2018), e que, por aproximadamente vinte e cinco anos, não foi registrada em capturas na região (Bertoletti e Lucena 1989; Beux e Zaniboni-Filho 2008). Diferentemente, no presente estudo, a espécie foi capturada nos anos 2008, 2009 e 2010. Uma possível explicação para esse resultado pode estar relacionada com escapes de tanques-rede pertencentes a cultivos comerciais realizados no reservatório (Beux et al. 2012).

Ainda quanto a influência de empreendimentos aquícolas na região, interessante também sublinhar a captura de quatros espécies exóticas: tilápia Oreochromis niloticus; bagre americano Ictalurus punctatus; carpas Ctenopharingodon idellus e Cyprinus carpio. A presença de espécies exóticas em ambiente natural é comum em muitos reservatórios neotropicais e ocorre principalmente por escapes das áreas de cultivo (Azevedo-Santos et al. 2011; Lockwood et al. 2009; Ortega et al. 2015). Padrão que se repete no presente estudo visto que a piscicultura regional utiliza as espécies citadas de forma rotineira (Silva, et al. 2017). Mais um dado para reforçar a visão da literatura que defende a importância de se redirecionar o foco da aquicultura para a produção de espécies nativas (Pelicice et al. 2014; Ortega et al. 2015).

As principais espécies responsáveis pela dissimilaridade entre os grupos foram apontadas pela análise SIMPER. Com representatividade crescente desde os anos iniciais até os anos finais de estudo, Acestrorbynchus pantaneiro, Iheringichthys labrosus, Schizodon nasutus, Parapimelodus valenciennis foram sobretudo importantes para explicar a diferença entre os grupos. Atenção também para as espécies Astyanax fasciatus, A. jacubiensis, A. scabripinnis e Bryconamericus iheringii, conhecidas como lambaris, que somaram quatro das 10 espécies mais representativas para a dissimilaridade, diminuindo suas contribuições ao longo dos anos. 
Estudos pretéritos mostraram o aumento expressivo da abundância do piscívoro sedentário Acestrorbynchus pantaneiro após a instalação da UHE Itá (Zaniboni-Filho et al. 2008) e da UHE Machadinho (Reynalte-Tataje et al. 2012b). No presente trabalho, a referida espécie somou elevadas capturas, sendo a primeira em biomassa e terceira em abundância numérica. A. pantaneiro parece ter sido favorecido pelo aumento populacional de espécies forrageiras, padrão recorrentemente descrito para espécies de peixes piscívoros em reservatórios (Loureiro-Crippa e Hahn 2006; Novakowski et al. 2007; Santos et al. 2017). A capacidade de adaptar sua alimentação de acordo com as presas mais abundantes nos reservatórios (Cantanhede et al. 2008) e táticas reprodutivas eficientes, que incluem desova parcelada com fecundidade relativamente alta e a ausência de cuidado parental (Meurer e Zaniboni-Filho 2012), parecem ter garantido a esta espécie uma boa adaptabilidade ao ambiente lêntico.

Por fim, outra espécie que parece ter sido favorecida com as novas condições impostas pelo reservatório foi a voga Schizodon nasutus. O crescimento de macrófitas aquáticas é fato comumente relatado em reservatórios brasileiros (Pelicice et al. 2008; Hermes-Silva e Zaniboni-Filho 2012) e constitui fonte de alimento abundante a esta espécie de hábito alimentar herbívoro (Andrade e Braga 2005; Villares-Junior et al. 2011). Também cabe relacionar o sucesso da espécie na colonização do reservatório à adaptações reprodutivas como desova parcelada, ausência de cuidado parental e comportamento não-migratório (Vazzoler e Menezes 1992; Nakatani et al. 2001).

\section{Conclusão}

Conclui-se que a assembleia de peixes do reservatório de Machadinho é uma comunidade moderadamente perturbada, dominada por espécies de pequeno porte, sobretudo caracídeos e pimelodídeos. A presença de espécies migradoras é rara e reflete o impacto da ausência de trechos lóticos bem estruturados necessários para que essas espécies completem seu ciclo de vida. A variação temporal da ictiofauna demonstrou claramente os impactos iniciais causados pelo barramento. A aparente estabilização que se seguiu foi novamente afetada no ano de 2006, como resultado do esvaziamento do reservatório da UHE Campos Novos, localizado à montante, cujas consequências incluíram maior abundância numérica de espécies com uma relação taxonômica mais estreita e a formação de uma assembleia com indicação de maiores perturbações. Com uma estrutura íctica mais semelhante, os últimos cinco anos mostraram nova tendência de estabilização no reservatório. Por fim, cabe observar que a UHE Machadinho faz parte de um sistema de reservatórios em cascata e, desta forma, sugere-se que, no futuro, novas investigações analisem estes sistemas de forma mais ampla, em escala espacial, buscando respostas que combinem os possíveis impactos das séries de barramentos.

\section{REFERÊNCIAS}

Agostinho AA, Gomes LC, Pelicice FM. 2007. Ecologia e manejo de recursos pesqueiros em reservatórios do Brasil. Maringá: Eduem. 501 p.

Agostinho AA, Gomes LC, Santos NCL, Ortega JCG, Pelicice FM. 2016. Fish assemblages in Neotropical reservoirs: Colonization patterns, impacts and management. Fisheries Research, 173(1):26-36. DOI: https://doi.org/10.1016/j. fishres.2015.04.006

Almeida APG, Behr ER, Baldisserotto B. 2013. Gill rakers in six teleost species: influence of feeding habit and body size. Ciência Rural, Santa Maria, 43(12):2208-2214. DOI: http://dx.doi.org/10.1590/S0103-84782013005000142 
Andrade PM, Braga FMS. 2005. Diet and feeding of fish from Grande River, located below the Volta Grande reservoir, MG-SP. Brazilian Journal of Biology, 65(3):377-385. DOI: http://dx.doi.org/10.1590/S1519-69842005000300002

Azevedo-Santos VM, Rigolin-Sá O, Pelicice FM. 2011. Growing, losing or introducing? Cage aquaculture as a vector for the introduction of non-native fish in Furnas Reservoir, Minas Gerais, Brazil. Neotropical Ichthyology, 9(4):915-919. DOI: http://dx.doi.org/10.1590/S1679-62252011000400024

Barbosa FAR, Padisak J, Espindola ELG, Borics G, Rocha O. 1999. The cascading reservoir continuum concept (CRCC) and its application to the river Tietê basin, São Paulo State, Brazil. In: Tundisi JG, Straukraba M (Eds), Theoretical Reservoir Ecology and its Applications, São Carlos: Internacional Institute of Ecology, São Carlos, BR, p. 425-437.

Bertoletti JJ, Lucena CAS. 1989. Ictiofauna da área de influência das UHEs de Itá e Machadinho, Relatório Final. Florianópolis: Puc/Cnec/Eletrosul.

Beux LF, Fracassoli DM, Zaniboni-Filho E, Nuñer APO. 2012. Criação de Piracanjuba (Brycon Orbignyanus) em tanquesrede. In: Nuñer APO, Zaniboni-Filho E (Eds), Reservatório de Machadinho: peixes, pesca e tecnologias de criação, Florianópolis: Ufsc, Florianópolis, BR, p. 179-204.

Beux LF, Zaniboni-Filho E. 2008. Produção pesqueira do reservatório de Itá, Alto Rio Uruguai. In: Zaniboni-Filho E, Nuñer APO (Eds), Reservatório de Itá: Estudos ambientais, desenvolvimento de tecnologias de cultivo e conservação da ictiofauna. Florianópolis: Ufsc, Florianópolis, BR, p. 87-108.

Cantanhede G, Hahn NS, Fugi R, Gubiani EA. 2008. Alterations on piscivorous diet following change in abundance of prey after impoundment in a Neotropical river. Neotropical Ichthyology, 6(4):631-636. DOI: http://dx.doi.org/10.1590/ S1679-62252008000400011

Clarke KR. 1990. Comparisons of dominance curves. Journal of Experimental Marine Biology and Ecology, 138(1):143157. DOI: https://doi.org/10.1016/0022-0981(90)90181-B

Clarke KR, Somerfield PJ, Warwick RM. 2014. Change in marine communities: an approach to statistical analysis and interpretation. 3nd ed. Plymouth: Primer-E. 262 p.

Clarke KR, Warwick RM. 2001. A further biodiversity index applicable to species lists: variation in taxonomic distinctness. Marine Ecology Progress series, 216:265-278. DOI: http://dx.doi.org/10.3354/meps216265

Clarke KR, Warwick RM. 1999. The taxonomic distinctness measure of biodiversity: weighting of step lenghs between hierarchical levels. Marine Ecology Progress series, 184:21-29. DOI: http://dx.doi.org/10.3354/meps184021

Dajoz R. 1973. Ecologia geral. São Paulo: Vozes Limitada, São Paulo, BR, 471 p.

Dias RM, Bailly D, Antônio RR, Suzuki HI, Agostinho AA. 2005. Colonization of the Corumbá Reservoir (Corumbá River, Paraná River Basin, Goiás State, Brazil) by the "lambari” Astyanax altiparanae (Tetragonopterinae; Characidae). Brazilian Archives of Biology and Technology, 48(3):467-476. DOI: http://dx.doi.org/10.1590/S1516-89132005000300017

Drastik V, Kubecka J, Tuser M, Cech M, Frouzova J, Jarolim O, Prchalova M. 2008. The effect of hydropower on fish stock: comparison between cascade and non-cascade reservoirs. Hydrobiologia, 609:25-36. DOI: https://doi.org/10.1007/ s10750-008-9393-1 
Empresa de Pesquisa Energética. 2017. Anuário Estatístico de Energia Elétrica 2017: ano base 2016. Rio de Janeiro: Epe, Rio de Janeiro, BR, 232 p.

Fernando CH, Holcik J. 1991. Fish in reservoirs. Internationale Revue der gesamten Hydrobiologie und Hydrographie, 76(2):149-167. DOI: https://doi.org/10.1002/iroh.19910760202

Godoy MP. 1987. Peixes do estado de Santa Catarina. Florianópolis: Ufsc/Eletrosul/Furb, Florianópolis, BR, 571 p.

Hermes-Silva S, Reynalte-Tataje DA, Abbud F, Zaniboni-Filho E. 2012. Ovos e Larvas de Peixes. In: Nuñer APO, ZaniboniFilho E (Eds), Reservatório de Machadinho: peixes, pesca e tecnologias de criação, Florianópolis: Ufsc, Florianópolis, BR, p. 83-106.

Hermes-Silva S, Zaniboni-Filho E. 2012. Structure of the litoral fish assemblage in an impounded tributary: the effects of macrophytes presence (subtropical region, Brazil). Brazilian Journal of Biology, 72(3):489-495. DOI: http://dx.doi. org/10.1590/S1519-69842012000300011

Hirt LM, Araya PR, Flores SA. 2011. Population structure, reproductive biology and feeding of Astyanax fasciatus (Cuvier, 1819) in an Upper Paraná River tributary, Misiones Argentina. Acta Limnologica Brasileira, 23(1):1-12. DOI: http:// dx.doi.org/10.4322/actalb.2011.013

Jorgensen S, Tundisi JG, Tundisi TM. 2013. Handbook of inland aquatic ecosystem management. Boca Raton: CRC Press, New York, USA, 422 p. https://www.taylorfrancis.com/books/9780429189395

Junk WJ, Bayley PB, Sparks RE. 1989. The flood pulse concept in river-floodplain systems. In: DODGE DP (Ed), Proceedings of the International Large River Symposium (LARS). Ottawa: Canadian Special Publication of Fisheries and Aquatic Sciences, Ottawa, CAN 106, p. 110-127.

Lasne E, Lek S, Laffaille P. 2007. Patterns in fish assemblages in the Loire floodplain: The role of Hydrological connectivity and implications for conservation. Biological Conservation, 139(3):258-268. DOI: https://doi.org/10.1016/j. biocon.2007.07.002

Lees AC, Peres CA, Fearnside PM, Schneider M, Zuanon JAS. 2016. A energia hidrelétrica e o futuro da Ama-biodiversidade zoniana. Biodiversidade e Conservação 25(3):451-466. DOI: https://doi.org/10.1007/s10531-016-1072-3

Lockwood JL, Cassey P, Blackburn TM. 2009. The more you introduce the more you get: the role of colonization pressure and propagule pressure in invasion ecology. Diversity and Distributions 15: 904-910. DOI: https://doi.org/10.1111/ j.1472-4642.2009.00594.x

Loureiro-Crippa VE, Hahn N. 2006. Use of food resources by the fish fauna of small reservoir (rio Jordão, Brazil) before and shortly after its filling. Neotropical Ichthyology, 4(3):357-362. DOI: http://dx.doi.org/10.1590/S1679-62252006000300007

Marques H, Dias JHP, Perbiche-Neves G, Kashiwaqui EAL, Ramos IP. 2018. Importance of dam-free tributaries for conserving fish biodiversity in neotropical reservoirs. Biological Conservation, 224:347-354. DOI: https://doi. org/10.1016/j.biocon.2018.05.027

Meurer S, Zaniboni-Fiho E. 2012. Reproductive and feeding biolgy of Acestrorbynchus pantaneiro Menezes, 1992 (Osteichthyes: Acestrorhynchidae) in areas under the influence of dams in the upper Uruguay River, Brazil. Neotropical Ichthyology, 10(1):159-166. DOI: http://dx.doi.org/10.1590/S1679-62252012000100015 
Ministério do Meio Ambiente. 2018. Livro Vermelho da Fauna Brasileira Ameaçada de Extinção: Volume I. Brasília: ICMBio/MMA, BR, 492 p. https://www.icmbio.gov.br/portal/images/stories/comunicacao/publicacoes/publicacoesdiversas/livro_vermelho_2018_vol1.pdf

Miranda LE, Dembkowski DJ. 2015. Evidence for serial discontinuity in the fish community of a heavily impounded river. River Research and Applications, 32(6):1187-1195. DOI: https://doi.org/10.1002/rra.2936

Nakatani K, Agostinho AA, Baumgartner G, Bialetzki A, Sanches PV, Makrakis MC, Pavanelli CS. 2001. Ovos e larvas de peixes de água doce: desenvolvimento e manual de identificação. Maringá: Eduem, Maringá, BR, 378 p.

Néspoli RS, Pizzato, R. 2007. Usina Hidrelétrica Machadinho: memória técnica. Florianópolis: NPE/UFSC, BR, 386 p. http://www.machadinho.com.br/novo/imprensa/publicacoes/1399986308.pdf

Novakowski GC, Hahn NS, Fugi R. 2007. Alimentação de peixes piscívoros antes e após a formação do reservatório de Salto Caxias, Paraná, Brasil. Biota Neotropica, 7(2):149-154. http://www.redalyc.org/articulo.oa?id=199114293017

Nuñer APO, Zaniboni-Filho E (Eds), 2012. Reservatório de Machadinho: peixes, pesca e tecnologias de criação. Florianopolis: Ufsc, Florianópolis, BR, 256 p.

Ortega JCG, Júlio HF, Gomes LC, Agostinho AA. 2015. Fish farming as the main driver of fish introductions in Neotropical reservoirs. Hydrobiologia, 746(1):147-158. DOI: https://doi.org/10.1007/s10750-014-2025-z

Pelicice FM, Thomaz SM, Agostinho AA. 2008. Simple relationships to predict attributes of fish assemblages in patches of submerged macrophytes. Neotropical Ichthyology, 6(4):543-550. DOI: http://dx.doi.org/10.1590/S1679-62252008000400001

Pelicice FM, Vitule JRS, Lima-Junior DP, Orsi ML, Agostinho AA. 2014. A Serious New Threat to Brazilian Freshwater Ecosystems: The Naturalization of Nonnative Fish by Decree. Conservation Letters, 7(1):55-60. DOI: https://doi. org/10.1111/conl.12029

Petesse ML, Petrere-Junior M. 2012. Tendency towards homogenization in fish assemblages in the cascade reservoir system of the Tiête river basin, Brazil. Ecological Engineering, 48:109-116. DOI: https://doi.org/10.1016/j.ecoleng.2011.06.033

Petrere-Junior M. 1996. Fisheries in large tropical reservoirs in South America. Lakes \& Reservoirs: Research and Management, 2(1):111-133. DOI: https://doi.org/10.1111/j.1440-1770.1996.tb00054.x

Reynalte-Tataje DA, Nuñer APO, Nunes MC, Garcia V, Lopes CA, Zaniboni-Filho E. 2012a. Spawning of migratory fish species between two reservoirs of the upper Uruguay River, Brazil. Neotropical ichthyology, 10(4):829-835. DOI: http:// dx.doi.org/10.1590/S1679-62252012000400016

Reynalte-Tataje DA, Zaniboni-Filho E, Bialetzki A, Agostinho AA. 2012b. Temporal variability of fish larvae assemblages: influence of natural and anthropogenic disturbances. Neotropical Ichthyology, 10(4):837-846. DOI: http://dx.doi. org/10.1590/S1679-62252012000400017

Santos NCL, Santana HS, Ortega JCG, Dias RM, Stegmann LF, Silva-Araújo IM, Severi W, Bini LM, Gomes LC, Agostinho AA. 2017. Environmental filters predict the trait composition of fish communities in reservoir cascades. Hydrobiologia, 802(1):245-253. DOI: https://doi.org/10.1007/s10750-017-3274-4 
Schork G, Hermes-Silva S, Beux LF, Zaniboni-Filho E, Nuñer APO. 2012. Diagnóstico da pesca artesanal na usina hidrelétrica de Machadinho, Alto rio Uruguai-Brasil. Boletim do Instituto de Pesca, 38(2):97-108. https://www.pesca. sp.gov.br/boletim/index.php/bip/article/view/948

Schork G, Hermes-Silva S, Zaniboni-Filho E. 2013. Analysis of fishing activity in the Itá reservoir, Upper Uruguay River, in the period 2004-2009. Brazilian Journal of Biology, 73(3):559-571. DOI: http://dx.doi.org/10.1590/S151969842013000300014

Schork G, Zaniboni-Filho E. 2017. Structure dynamics of a fish community over ten years of formation in the reservoir of the hydroelectric power plant in Itá. Brazilian Journal of Biology, 77(4):710-723. DOI: http://dx.doi.org/10.1590/15196984.17015

Schork G, Zaniboni-Filho E. 2018. Influence of spatial gradient caused by a large dam on fish assemblage in a subtropical reservoir - Upper Uruguay River. Boletim do Instituto de Pesca 44(2):1/e236-11. https://www.pesca.sp.gov.br/boletim/ index.php/bip/article/view/1289

Secretária do Estado do Desenvolvimento Urbano e Meio Ambiente (SDM). 1997. Bacias hidrográficas de Santa Catarina: diagnóstico geral. Florianópolis: Governo do Estado de Santa Catarina, Florianópolis, BR. 163 p.

Silva BC, Giustina EGD, Marchiori NC, Massago H, Silva FM. 2017. Desempenho produtivo da piscicultura catarinense em 2015. Epagri, Florianópolis, BR, 17 p. http://publicacoes.epagri.sc.gov.br/index.php/DOC/article/view/512/402

Straskraba M. 1990. Limnological particularities of multiple reservoir series. Archiv fur Hydrobiologie Beiheft Ergebnisse der Limnologie, vol. 33, pp. 677-678.

Vannote RL, Minshall JV, Cummins KW, Seddell JR, Cushing CE. 1980. The river continuum concept. Canadian Journal of Fisheries and Aquatic Sciences, 37(1):130-137. DOI: https://doi.org/10.1139/f80-017

Vazzoler AEAM, Menezes NA. 1992. Síntese de conhecimento sobre o comportamento reprodutivo dos Characiformes da América do Sul (Teleostei: Characiformes). Revista Brasileira de Biologia, 52(4):627-640.

Villares-Junior GA, Gomiero LM, Goitein R. 2011. Biological aspects of Scbizodon nasutus Kner, 1958 (Characiformes: Anostomidae) in the low Sorocaba river basin, São Paulo state, Brazil. Brazilian Journal of Biology, 71(3):763-770. DOI: http://dx.doi.org/10.1590/S1519-69842011000400023

Ward JV, Stanford JA. 1995. The serial discontinuity concept: extending the model to floodplain rivers. Regulated Rivers: Research \& Management, 10(2-4):159-168. DOI: https://doi.org/10.1002/rrr.3450100211

Warwick RM. 1986. A new method for detecting pollution effects on marine macrobenthic communities. Marine Biology, 92(4):557-562. DOI: https://doi.org/10.1007/BF00392515

Winemiller KO, McIntyre PB, Castello L, Fluet-Chouinard E, Giarrizzo T, Nam S, Baird IG, Darwall W, Lujan NK, Harrison I, Stiassny MLJ, Silvano RAM, Fitzgerald DB, Pelicice FM, Agostinho AA, Gomes LC, Albert JS, Baran E, PetrereJr. M, Zarfl C, Mulligan M, Sullivan JP, Arantes CC, Sousa LM, Koning AA, Hoeinghaus DJ, Sabaj M, Lundberg JG, Armbruster J, Thieme ML, Petry P, Zuanon J, Torrente Vilara G, Snoeks J, Ou C, Rainboth W, Pavanelli CS, Akama A, van Soesbergen A, Sáenz L. 2016. Balancing hydropower and biodiversity in the Amazon, Congo, and Mekong. Science, 351(6269):128-129. DOI: 10.1126/science.aac7082 
Zaniboni-Filho E, Schulz UH. 2003. Migratory fishes of the Uruguay river. In: Carlosfeld J, Harvey B, Baer A, Ross C (Eds), Migratory fishes of the South América: biology, social importance and conservation status. Victoria: World Fisheries Trust, Victoria, CAN, p. 135-168.

Zaniboni-Filho E, Nuñer APO (Eds), 2008. Reservatório de Itá: Estudos ambientais, desenvolvimento de tecnologias de cultivo e conservação da ictiofauna. Florianópolis: Ufsc, Florianópolis, BR.

Zaniboni-Filho E, Meurer S, Shibatta AO, Nuñer APO. 2004. Catálogo ilustrado de peixes do alto rio Uruguai. Florianópolis: Ufsc/Tractebel Energia, Florianópolis, BR. 128 p.

Zaniboni-Filho E, Nuñer APO, Reynate-Tataje DA, Hermes-Silva S, Meurer S. 2008. Alterações espaciais e temporais da estrutura da comunidade de peixes em decorrência da implantação do reservatório de Itá (Alto Rio Uruguai). In: ZaniboniFilho E, Nuñer APO (Eds), Reservatório de Itá: Estudos ambientais, desenvolvimento de tecnologias de cultivo e conservação da ictiofauna. Florianópolis: Ufsc, Florianópolis, BR. p. 21-48.

Zarfl C, Lumsdon AE, Berlekamp J, Tydecks L, Tockner K. 2014. A global boom in hydropower dam construction. Aquatic Sciences, 77(1):161-170. DOI:10.1007/s00027-014-0377-0

\section{ANEXOS}

Anexo I - Datas de realização das coletas no reservatório da UHE Machadinho no período compreendido entre 2002 e 2011. Asterisco vermelho indica quando ocorreu o esvaziamento do reservatório da UHE Campos Novos, localizada a montante da UHE Machadinho.

\begin{tabular}{|c|c|c|}
\hline Ano & Estação & Dia / Mês \\
\hline \multirow{4}{*}{2002} & Verão & $04-09 / \mathrm{fev}$ \\
\hline & Outono & 05-09/mai \\
\hline & Inverno & 05-09/ago \\
\hline & Primavera & $14-18 /$ out \\
\hline \multirow{4}{*}{2003} & Verão & $10-14 / \mathrm{fev}$ \\
\hline & Outono & $23-27 / \mathrm{abr}$ \\
\hline & Inverno & 05-09/ago \\
\hline & Primavera & 27-31/out \\
\hline \multirow{5}{*}{2004} & \multirow{2}{*}{ Verão } & 29-31/jan \\
\hline & & $01-02 / \mathrm{fev}$ \\
\hline & Outono & $13-17 / \mathrm{abr}$ \\
\hline & Inverno & 02-06/ago \\
\hline & Primavera & 14-18/out \\
\hline \multirow{5}{*}{2005} & Verão & $11-15 / \mathrm{fev}$ \\
\hline & \multirow{2}{*}{ Outono } & 28-31/mar \\
\hline & & $01 / \mathrm{abr}$. \\
\hline & Inverno * & 20-24/jun \\
\hline & Primavera & $21-26 /$ nov \\
\hline
\end{tabular}

\begin{tabular}{|c|c|c|}
\hline Ano & Estação & Dia / Mês \\
\hline \multirow{6}{*}{2006} & \multirow{2}{*}{ Verão } & $30-31 /$ jan \\
\hline & & $01-04 / \mathrm{fev}$ \\
\hline & \multirow{2}{*}{ Outono } & $27-30 / \mathrm{mar}$ \\
\hline & & 01/abr. \\
\hline & Inverno & 15-20/ago \\
\hline & Primavera & $11-15 /$ out \\
\hline \multirow{6}{*}{2007} & Verão & $06-10 / \mathrm{fev}$ \\
\hline & Outono & $01-06 / \mathrm{mai}$ \\
\hline & \multirow{2}{*}{ Inverno } & 31/jul. \\
\hline & & 01-04/ago \\
\hline & \multirow{2}{*}{ Primavera } & 30-31/out \\
\hline & & $01-04 /$ nov \\
\hline \multirow{4}{*}{2008} & Verão & $04-08 / \mathrm{fev}$ \\
\hline & Outono & $01-05 / \mathrm{mai}$ \\
\hline & Inverno & $22-27 / \mathrm{jul}$ \\
\hline & Primavera & $04-10 /$ nov \\
\hline
\end{tabular}

\begin{tabular}{|c|c|c|}
\hline Ano & Estação & Dia / Mês \\
\hline \multirow{5}{*}{2009} & Verão & $03-07 / \mathrm{fev}$ \\
\hline & Outono & 05-09/mai \\
\hline & \multirow{2}{*}{ Inverno } & 31/jul. \\
\hline & & 01-03/ago \\
\hline & Primavera & 03-07/nov \\
\hline \multirow{5}{*}{2010} & Verão & $02-06 / \mathrm{fev}$ \\
\hline & Outono & 05-09/mai \\
\hline & Inverno & 04-08/ago \\
\hline & \multirow{2}{*}{ Primavera } & 31/out. \\
\hline & & $01-07 /$ nov \\
\hline \multirow{5}{*}{2011} & Verão & $08-13 / \mathrm{fev}$ \\
\hline & Outono & 09-13/mai \\
\hline & \multirow{2}{*}{ Inverno } & 31/jul. \\
\hline & & 01-03/ago \\
\hline & Primavera & 26-30/out \\
\hline
\end{tabular}


Anexo II - Abundância absoluta e relativa para número de indivíduos [n e n(\%)] e biomassa [B(kg) e B(\%)] de cada espécie, número de voucher cadastrado no Museu de Zoologia da Universidade Estadual de Londrina (MUZEL), além da constância de Dajoz, para as capturas realizadas no reservatório da UHE Machadinho no período compreendido entre 2002 e 2011 (Cons - constante, Aces - acessória, Acid - acidental).

\begin{tabular}{lcllllll}
\hline Nome científico & $\begin{array}{c}\text { n voucher } \\
\text { MZUEL }\end{array}$ & $\mathrm{n}$ & $\mathrm{n}(\%)$ & $\mathrm{B}(\mathrm{kg})$ & $\mathrm{B}(\%)$ & Cons \\
\hline
\end{tabular}

\section{Atherinopsidae \\ Odontesthes perugiae Evermann \& Kendall 1906 \\ CHARACIFORMES}

Acestrorhynchidae

Acestrorbynchus pantaneiro Menezes 1992

Anostomidae

Leporinus amae Godoy 1980

Megaleporinus obtusidens (Valenciennes 1837)

Schizodon nasutus Kner 1858

Bryconidae

Brycon orbignyanus (Valenciennes 1850)

Salminus brasiliensis (Cuvier 1816)

\section{Characidae}

Astyanax fasciatus (Cuvier 1819)

Astyanax scabripinnis (Jenyns 1842)

Astyanax jacubiensis (Cope 1894)

Bryconamericus iheringii (Boulenger 1887)

Bryconamericus stramineus Eigenmann 1908

Cynopotamus kincaidi (Schultz 1950)

Galeocharax humeralis (Valenciennes 1834)

Oligosarcus brevioris Menezes 1987

Oligosarcus jenynsii (Günther 1864)

Serrasalmidae

Pygocentrus nattereri Kner 1858

Serrasalmus maculatus Kner 1858

Curimatidae

Steindachnerina biornata (Braga \& Azpelicueta 1987)

Steindachnerina brevipinna (Eigenmann \&

Eigenmann 1889)

\section{Erythrinidae}

Hoplias lacerdae Miranda Ribeiro 1908

Hoplias malabaricus (Bloch 1794)

Paradontidae

Apareiodon affinis (Steindachner 1879)

Prochilodontidae
Astyanax eigenmanniorum (Cope 1894)

3615

1

15715

2783

6,76

372,8

14,68 Cons

$\begin{array}{cccccc}15732 & 219 & 0,53 & 12,23 & 0,48 & \text { Acid } \\ 18970 & 1 & 0 & 3,18 & 0,13 & \text { Acid } \\ 15627 & 1854 & 4,5 & 265,4 & 10,45 & \text { Cons }\end{array}$

17120

15570

15

0,01
0,04

11,8

0,46

Acid

15

16999

10234

16870

15707

15595

15591

15564

15563

15600

15586

62

0,15

65,65

2,59 Acid

21425,2

23,75

1,07

0,04 Acid

168,89

6,65 Cons

223

2232

5,42

35,75

1,41 Aces

2054

25,56

1,01 Cons

45

457

4,99

2,65

0,1 Cons

1,11

0,22

0,01 Acid

10

0,02

1,11

0,04 Acid

108

0,26

9,38

0,37 Acid

33

0,08

1,51

0,06

Acid

13743,3

15562

15733

70

$0,02 \quad 2,86$

0,11 Acid

0,12

19,48

0,77 Acid

10289

15784

2376

0,2

1,78

0,07

Acid

15719

15751

121

0,29

97,02

3,82 Aces

242

0,59

166,03

6,54 Cons

15589

21

0,5

2,01

0,08 Aces

Prochilodus lineatus (Valenciennes 1837)

$10 \quad 0,02 \quad 28,93$

1,14 Acid




$\begin{array}{lclllll}\text { Nome científico } & \text { n voucher } & \text { MZUEL } & n & n(\%) & B(k g) & B(\%)\end{array}$

\section{CYPRINIFORMES}

\section{Cyprinidae}

Ctenopharyngodon idella (Valenciennes 1844)

não preservado $\quad 8 \quad 0,02 \quad 26,82 \quad 1,06 \quad$ Acid

Cyprinus carpio Linnaeus 1758

11730

$191 \quad 0,46 \quad 229,09 \quad 9,02 \quad$ Aces

\section{CYPRINODONTIFORMES}

Poeciliidae

Phalloceros caudimaculatus (Hensel 1868)

15592

$1 \quad 0$

0

$0 \quad$ Acid

\section{GYMNOTIFORMES}

\section{Gymnotidae}

Gymnotus carapo Linnaeus 1758

15559

$4 \quad 0,01 \quad 0,18 \quad 0,01 \quad$ Acid

Sternopygidae

Eigenmannia virescens (Valenciennes 1836)

15785

$\begin{array}{lllll}110 & 0,27 & 2,64 & 0,1 & \text { Acid }\end{array}$

\section{PERCIFORMES}

\section{Cichlidae}

Crenicichla celidochilus Casciotta 1987

Crenicichla igara Lucena \& Kullander 1992

\begin{tabular}{lccccc}
15708 & 28 & 0,07 & 3,41 & 0,13 & Acid \\
15730 & 34 & 0,08 & 4,34 & 0,17 & Acid \\
05390 & 14 & 0,03 & 1,17 & 0,05 & Acid \\
18977 & 15 & 0,04 & 1,19 & 0,05 & Acid \\
15598 & 56 & 0,14 & 4,16 & 0,16 & Acid \\
15731 & 2 & 0 & 0,12 & 0 & Acid \\
15727 & 11 & 0,03 & 0,55 & 0,02 & Acid \\
15718 & 503 & 1,22 & 9,82 & 0,39 & Cons \\
15628 & 2 & 0 & 0 & 0 & Acid \\
16646 & 2 & 0 & 0,01 & 0 & Acid \\
\hline & & & & &
\end{tabular}

Crenicichla jurubi Lucena \& Kullander 1992

Crenicichla minuano Lucena \& Kullander 1992

Crenicichla missioneira Lucena \& Kullander 1992

Crenicichla tendybaguassu Lucena \& Kullander 1992

Crenicichla vittata Heckel 1840

Geophagus brasiliensis (Quoy \& Gaimard, 1824)

Gymnogeophagus gymnogenys (Hensel 1870)

Oreochromis niloticus (Linnaeus 1758)

\section{SILURIFORMES}

\section{Auchenipteridae}

Trachelyopterus teaguei (Devincenzi 1942)

$\begin{array}{llllll}\text { não preservado } & 1 & 0 & 0,06 & 0 & \text { Acid }\end{array}$

Callichthyidae

Corydoras paleatus (Jenyns 1842)

15568

$55 \quad 0,13 \quad 0,11 \quad 0 \quad$ Acid

Heptapteridae

Rhamdella longiuscula Lucena \& da Silva 1991

Rhamdia quelen (Quoy \& Gaimard 1824)

$\begin{array}{cccccc}15714 & 29 & 0,07 & 1,09 & 0,04 & \text { Acid } \\ 10549 & 307 & 0,75 & 70,89 & 2,79 & \text { Cons } \\ \text { não preservado } & 1 & 0 & 0,01 & 0 & \text { Acid }\end{array}$

Pimelodella sp.

Ictaluridae

Ictalurus punctatus (Rafinesque, 1818)

$\begin{array}{llllll}\text { não preservado } & 1 & 0 & 0,04 & 0 & \text { Acid }\end{array}$ 


\begin{tabular}{|c|c|c|c|c|c|c|}
\hline Nome científico & $\begin{array}{l}\text { n voucher } \\
\text { MZUEL }\end{array}$ & $\mathrm{n}$ & $\mathrm{n}(\%)$ & $\mathrm{B}(\mathrm{kg})$ & $\mathrm{B}(\%)$ & Cons \\
\hline \multicolumn{7}{|l|}{ Loricariidae } \\
\hline Ancistrus sp. & 16992 & 1 & 0 & 0,02 & 0 & Acid \\
\hline Ancistrus taunayi Miranda Ribeiro 1918 & 15565 & 2 & 0 & 0,04 & 0 & Acid \\
\hline Pogonopoma obscurum Quevedo \& Reis 2002 & 15729 & 214 & 0,52 & 63,65 & 2,51 & Aces \\
\hline $\begin{array}{l}\text { Hemiancistrus fuliginosus Cardoso \& Malabarba } \\
1999\end{array}$ & 16651 & 73 & 0,18 & 2,22 & 0,09 & Aces \\
\hline Pareiorhaphis sp & não preservado & 1 & 0 & 0,02 & 0 & Acid \\
\hline Hypostomus commersoni Valenciennes 1836 & 10240 & 231 & 0,56 & 67,67 & 2,66 & Cons \\
\hline $\begin{array}{l}\text { Hypostomus isbrueckeri Reis, Weber \& Malabarba } \\
1990\end{array}$ & 10239 & 898 & 2,18 & 93,82 & 3,69 & Cons \\
\hline Hypostomus luteus (Godoy 1980) & 10279 & 42 & 0,1 & 10,53 & 0,41 & Acid \\
\hline Hypostomus regani (Ihering 1905) & 10251 & 6 & 0,01 & 1,29 & 0,05 & Acid \\
\hline $\begin{array}{l}\text { Hypostomus roseopunctatus Reis, Weber \& } \\
\text { Malabarba } 1990\end{array}$ & 10242 & 45 & 0,11 & 5,76 & 0,23 & Acid \\
\hline $\begin{array}{l}\text { Hypostomus uruguayensis Reis, Weber \& Malabarba } \\
1990\end{array}$ & 19134 & 1 & 0 & 0,14 & 0,01 & Acid \\
\hline Loricariichthys anus (Valenciennes 1835) & 15629 & 6 & 0,01 & 0,16 & 0,01 & Acid \\
\hline Rineloricaria sp. & 15571 & 6 & 0,01 & 0,06 & 0 & Acid \\
\hline \multicolumn{7}{|l|}{ Pimelodidae } \\
\hline Iheringichthys labrosus (Lütken 1874) & 15608 & 899 & 2,18 & 85,4 & 3,36 & Cons \\
\hline Parapimelodus valenciennis (Lütken 1874) & 15749 & 10292 & 25 & 140,31 & 5,53 & Cons \\
\hline Pimelodus absconditus Azpelicueta 1995 & 15709 & 76 & 0,18 & 4,5 & 0,18 & Aces \\
\hline Pimelodus atrobrunneus Vidal \& Lucena 1999 & 15740 & 65 & 0,16 & 2,51 & 0,1 & Acid \\
\hline Pimelodus maculatus Lacepède 1803 & 15606 & 677 & 1,64 & 180,82 & 7,12 & Cons \\
\hline Steindachneridion scriptum (Miranda Ribeiro 1918) & 15569 & 24 & 0,06 & 36,03 & 1,42 & Acid \\
\hline
\end{tabular}

